\title{
An evaluation of cerebrospinal fluid oligoclonal banding confirmed by immunofixation on agarose gel
}

\author{
PM GEORGE, ${ }^{*}$ MA LORIER, ${ }^{*}$ IMacG DONALDSON†
}

\begin{abstract}
From the Department of Clinical Biochemistry, ${ }^{*}$ and Department of Neurology, $\dagger$ Christchurch Hospital, Christchurch, New Zealand
\end{abstract}

SUMMARY The cerebrospinal fluid (CSF) from 115 consecutive patients undergoing diagnostic lumbar puncture or myelography was examined to determine the usefulness of immunofixation, following agarose gel electrophoresis, in the detection of oligoclonal IgG. All electrophoretic patterns were evaluated with and without immunofixation, and the interpretation of $9 \%$ of specimens was altered by immunofixation. The demonstration of oligoclonal IgG was shown to be more reliable in the diagnosis of multiple sclerosis than other indices of intrathecal synthesis of IgG. It is concluded that immunofixation should be used routinely when examining CSF for oligoclonal banding.

The diagnosis of multiple sclerosis on clinical grounds alone is often difficult and there is need for a reliable laboratory test for the disease. The demonstration of oligoclonal bands of $\mathrm{IgG}$ in the cerebrospinal fluid (CSF) has been shown to be useful in confirming the diagnosis. ${ }^{12}$ These bands can be demonstrated by polyacrylamide gel electrophoresis (PAGE) ${ }^{3}$ agarose gel electrophoresis ${ }^{1}$ and isoelectric focusing. ${ }^{4}$ The latter two methods are probably more sensitive than PAGE. ${ }^{4-6}$ In an attempt to increase sensitivity further we have combined agarose gel electrophoresis of the CSF with the routine use of immunofixation to positively identify the oligoclonal bands as IgG. Although this technique has been advocated to help resolve equivocal electrophoretic patterns, ${ }^{78}$ it has not previously been applied to all samples in a series. Earlier reports have assumed that many of the patients' oligoclonal bands are IgG without definitely identifying them in each CSF. We wished to see if the routine application of immunofixation would not only clarify equivocal patterns but also correct unappreciated misinterpretation of specimens.

Interpretation of electrophoretic patterns is subjective and knowledge of the clinical diagnosis and of other CSF parameters might influence the results. In order to eliminate this possibility, all elec-

Address for reprint requests: Dr PM George, Department of Clinical Biochemistry, Christchurch Hospital, Christchurch, New Zealand.

Received 2 December 1982

Accepted 7 February 1983 trophoretic results were interpreted, without this other information. This is the first time that such a coded evaluation has been reported. In order to assess the significance of the presence of oligoclonal bands in neurological disorders, the CSF was examined from all patients in a neurological unit of a general hospital who underwent diagnostic lumbar puncture or myelography over the period of the study.

Earlier CSF tests for multiple sclerosis, such as IgG/albumin ratio, ${ }^{9}$ IgG index, ${ }^{10}$ and IgG synthesis, ${ }^{11}$ depend on the amount, rather than the type, of IgG in the CSF. The relative importance of oligoclonal bands has not always been clear. ${ }^{212}$ In order to assess this we have compared these tests with oligoclonal bands in the same patients.

\section{Material and methods}

\section{Patients}

In 115 consecutive patients admitted to a neurology ward, who had a lumbar puncture or myelogram as part of their investigations, samples of CSF $(5 \mathrm{ml})$ and serum $(5 \mathrm{ml})$ were obtained. There was no selection or exclusion of samples or patients except by availability of CSF. Lumbar puncture was done using the standard technique between the L3-4 or L4-5 interspace. A few of the myelograms were performed by high lateral cervical puncture. All patients had presented as diagnostic problems, and none of the cases of multiple sclerosis were in the longstanding definite group. Patients in whom a diagnosis of multiple sclerosis could be entertained were separately classified according to both the criteria of McAlpine ${ }^{13}$ and McDonald and Halliday. ${ }^{14}$ The latter classification allows 
the inclusion of electrophysiological as well as clinical evidence of multiple sclerosis and thus results in more cases falling into the definite group. The presence or absence of oligoclonal bands was not considered in classifying these cases.

\section{Protein assays}

The concentrations of IgG and albumin in CSF and serum were determined in one run by electroimmunoassay ${ }^{15}$ using antisera obtained from DAKOPATTS (DK-200) Copenhagen, Denmark). The CSF IgG/Albumin ratio,? IgG Index, ${ }^{10}$ and IgG Synthesis ${ }^{11}$ were calculated from these values.

\section{Agarose electrophoresis and immunofixation}

CSF specimens were concentrated by ultrafiltration in colloidon bags (Sartorius Membranfilter, D-3400, Göttingen, W Germany) to a protein concentration of about $80 \mathrm{~g} / \mathrm{l}$. Concentrated CSF and serum $(2 \mu \mathrm{l})$ were applied to agarose gel with the aid of a mask. ${ }^{16}$ In addition five doubling dilutions of the concentrated CSF (in isotonic saline) were applied, in parallel, to the agarose. Agarose gel (Miles Laboratories Pty Ltd, Goodwood CP7460, South Africa) was $1 \%$ in $0.1 \mathrm{M} / \mathrm{l}$ Tris-Barbitone buffer, $\mathrm{pH} 8.6$, supported on Gelbond (FMC Corporation, Rockland, Me 04841, USA). After electrophoresis as described by Jeppsson $e t a^{16}$ the gels were cut and the diluted specimens immunofixed $^{17}$ with anti-IgG antisera (DAKOPATTS). The remaining gel was fixed in saturated picric acid/acetic acid $(4: 1)$. Prior to interpretation gels were stained for protein with Coomassie Brilliant Blue $\mathbf{R}$, and destained in ethanol/acetic acid/water (9:2:9).

Electrophoretic patterns were evaluated for oligoclonal bands without knowledge of clinical, or other CSF, data. Separate evaluations for each sample were made by two observers, one interpreting with, and one without, the aid of immunofixation.
Patients who had two or more bands confirmed as IgG in CSF, but not in serum, were classified as positive for CSF oligoclonal IgG. All other CSF specimens were considered negative. There were several CSF specimens in which a monoclonal band was present in both CSF and serum. These were considered to be negative.

\section{Results}

We examined 121 consecutive CSF specimens from 115 patients. In 43 patients a diagnosis of multiple sclerosis could be considered by the criteria of McAlpine, ${ }^{13}$ and McDonald and Halliday. ${ }^{14}$ The division by these classifications, and the numbers positive for oligoclonal bands are shown in table 1 . The sensitivity for definite multiple sclerosis is $100 \%$, and less in the probable and possible categories. Of the remaining 72 patients (table 2) with other neurological disorders, two had positive oligoclonal bands. In these patients the diagnoses were neurosyphilis and recurrent Guillian-Barré syndrome, conditions known to have CSF oligoclonal bands. ${ }^{818}$ There were monoclonal IgG bands in CSF and serum in five cases, a monoclonal IgM in CSF only in one case and an unidentified band which was not an immunoglobulin in 55 cases. This unidentified band, which is cathodal, variable and not in the position of $\gamma$-trace or the Tau transferrin, has been described previously. ${ }^{19}$ In cases with positive oligoclonal bands, three or more bands of $\mathrm{IgG}$ unique to CSF were demonstrated except in the patient with neurosyphilis (two bands).

A comparison of oligoclonal bands classified after electrophoresis, and after electrophoresis plus

Table 1 Oligoclonal banding in multiple sclerosis patients by classifications

\begin{tabular}{lllll}
\hline McAlpine classification & & Definite & Probable & Possible \\
\hline $\begin{array}{l}\text { No of patients } \\
\text { Positive oligoclonal banding }\end{array}$ & 12 & 9 & 22 \\
$\begin{array}{l}\text { McDonald \& Halliday } \\
\begin{array}{l}\text { Classification } \\
\text { No of patients }\end{array}\end{array}$ & $\begin{array}{l}\text { Clinically } \\
\text { definite }\end{array}$ & $\begin{array}{l}\text { Early probable } \\
\text { or latent }\end{array}$ & $\begin{array}{l}\text { Progressive } \\
\text { probable }\end{array}$ & Suspected \\
\hline
\end{tabular}

There were no cases in the progressive possible category of McDonald \& Halliday.

Table 2 Oligoclonal banding classified by: (A) electrophoresis and immunofixation or (B) electrophoresis alone

\begin{tabular}{lcccc}
\hline & Definite & Probable & Possible & $\begin{array}{l}\text { Neurological } \\
\text { controls }\end{array}$ \\
\hline No of patients & 12 & 9 & 22 & 72 \\
Positive oligoclonal banding by A & 12 & 8 & 10 & 2 \\
Positive oligoclonal banding by B & 12 & 4 & 8 & 2 \\
Equivocal oligoclonal banding by B & 0 & 3 & $1^{*}$ & $1 \dagger$ \\
\hline
\end{tabular}

*Clinical diagnosis of post-infectious cerebellitis.

tClinical diagnosis of motor neurone disease. 
Table 3 Results of all tests in patients classified according to the McAlpine criteria ${ }^{13}$

\begin{tabular}{llllc}
\hline & Definite & Probable & Possible & $\begin{array}{l}\text { Neurological } \\
\text { controls }\end{array}$ \\
\hline Oligoclonal banding & 12 & 8 & 10 & 2 \\
IgG/Albumin $>0 \cdot 16$ & $12(12)$ & $8(8)$ & $17(9)$ & $25(2)$ \\
IgG Index $>0 \cdot 6$ & $11(11)$ & $7(6)$ & $13(8)$ & $23(2)$ \\
IgG Synthesis $>6 \mathrm{mg}$ /day & $12(12)$ & $7(5)$ & $7(6)$ & $14(2)$ \\
\hline
\end{tabular}

(N) No which also had Oligoclonal banding

immunofixation is shown in table 2. There were two patients in whom oligoclonal bands appeared positive on electrophoresis but this was not IgG on immunofixation. In these two cases the clinical diagnoses were post-infectious cerebellitis and motor neuron disease. In three other patients oligoclonal bands were demonstrated by immunofixation but not detected by electrophoresis alone. In five patients oligoclonal bands, equivocal after electrophoresis, were clearly demonstrated by immunofixation. In all cases of disagreement the interpretation after immunofixation appeared to be the correct one.

In the six patients who had two samples of CSF analysed the specimens demonstrated the same pattern of oligoclonal IgG in five cases. The other patient, who had definite multiple sclerosis, had an incidental viral meningitis at the time of the first lumbar puncture and negative oligoclonal bands. After the meningitis had settled a repeat examination showed positive oligoclonal bands. In the first sample exudated serum proteins were present in the $\mathrm{CSF}$ and probably concealed the presence of oligoclonal bands.

The results of the IgG and albumin determinations are shown in table 3 .

\section{Discussion}

This study allows critical evaluation of the usefulness of CSF electrophoresis with immunofixation in routine neurological practice. The spectrum of neurological disorders in which CSF is usually examined was covered by including all patients undergoing lumbar puncture or myelography during the study. Unlike some other series, ${ }^{3}$ no samples were excluded on technical grounds. Immunofixation, unlike PAGE, is not subject to interference from haptoglobin in the CSF. In addition some other studies of oligoclonal bands have contained a substantial proportion of patients with long standing definite multiple sclerosis. ${ }^{12}{ }^{19}$ The clinical value of a test for multiple sclerosis in such patients may be questioned. The present series contains no such patients and in those with definite multiple sclerosis the patients moved into this category because of the relapse which led to their investigation. The "blind" interpretation of electrophoretic patterns excludes the possibility of observer bias.

We found that with electrophoresis alone, many cases were difficult to interpret, and that immunofixation always resolved this. In fact, the use of this technique resulted in correction of misinterpretation of five samples (see Results). In a further five cases oligoclonal bands were equivocal after electrophoresis but clearly shown to be positive on immunofixation. The routine use of this technique thus altered interpretation in $9 \%$ of patients. These findings are in contrast to a recent report that immunofixation did not improve the detection of oligoclonal bands with a commerical agarose gel system..$^{20}$ Immunofixation not only allows the immunoglobulin contents of oligoclonal bands to be positively identified but also gives a 20 -fold increase in the sensitivity for detecting them. ${ }^{17}$ Testing serial 2-fold dilutions optimises this.

The apparent sensitivity of any test for multiple sclerosis is influenced by the clinical criteria which are used to divide patients into various groups. Although previous studies using other techniques have reported oligoclonal bands in $72 \%$ to $100 \%$ of multiple sclerosis patients some have not defined the criteria for the diagnosis. ${ }^{52122}$ Our finding of $100 \%$ sensitivity for definite multiple sclerosis and $89 \%$ sensitivity for probable multiple sclerosis compares favourably with other studies and supports recent claims that the use of electrophoresis on agarose gel is a more sensitive and specific test for oligoclonal bands, and appears more effective than quantitative estimation of IgG in multiple sclerosis.

The relative value of quantification of CSF IgG by the derived indices of IgG/albumin ratio, IgG index and IgG synthesis has been questioned. ${ }^{2}{ }^{1222}$ These derived indices for the 115 patients are shown in table 3. An assessment of the reliability of any test depends on accurately identifying all patients with the disease by other means. This cannot be done in multiple sclerosis and an uncertain number in the possible and probable categories may not have the disease. If, however, we assume that all patients under clinical suspicion of having multiple sclerosis, that is the definite, probable and possible groups, do have it and that none of the neurological controls do, then we can assess the relative reliabilities of 
Table 4 The test parameters which determine the relative value of all tests for multiple sclerosis

\begin{tabular}{|c|c|c|c|c|}
\hline & Oligoclonal banding & $\begin{array}{l}\text { IgG/Albumin } \\
(>0 \cdot 16)\end{array}$ & $\begin{array}{l}G \text { index } \\
(>0 \cdot 6)\end{array}$ & $\begin{array}{l}\text { G synthesis } \\
\text { (>6 mg/day) }\end{array}$ \\
\hline $\begin{array}{l}\text { Specificity }{ }^{*} \\
\text { Predictive value of a positive test } \dagger \\
\text { Predictive value of a negative test } \ddagger \\
\text { Efficiency } \S\end{array}$ & $\begin{array}{l}97 \\
93 \\
84 \\
86\end{array}$ & $\begin{array}{l}65 \\
59 \\
88 \\
73\end{array}$ & $\begin{array}{l}68 \\
57 \\
80 \\
69\end{array}$ & $\begin{array}{l}80 \\
65 \\
77 \\
73\end{array}$ \\
\hline
\end{tabular}

Test parameters as defined by Galen and Gambino. ${ }^{23}$

*\% of neurological controls with a normal test.

†\% of all patients with an abnormal test who are "under suspicion of multiple sclerosis".

$\ddagger \%$ of all patients with a normal test who do not have multiple sclerosis.

$\S \%$ of all 115 patients correctly classified into groups, of "under suspicion of multiple sclerosis" and neurological controls, by the tests.

these tests. Thus the specificity, the predictive values of positive and negative tests, and the efficiencies of these tests $\mathrm{s}^{23}$ are shown in table 4 . These confirm the superior discrimination of oligoclonal bands in multiple sclerosis. The real value of this test depends on whether it selectively identifies those patients in the possible and probable multiple sclerosis groups, who will eventually turn out to have multiple sclerosis. This can only be determined by follow up. At the present time the demonstration of oligoclonal bands of IgG appears to be the most reliable CSF test for multiple sclerosis, and we recommend electrophoresis on agarose gel using routine immunofixation to aid interpretation.

We acknowledge the expert technical assistance of JM Sheat and thank Dr PJ Parkin for advice on the manuscript and for allowing his patients to be included in the study.

\section{References}

${ }^{1}$ Link H, Tibbling G. Principles of Albumin and IgG analyses in Neurological Disorders III. Evaluation of IgG Synthesis within the central nervous system in Multiple Sclerosis. Scand J Clin Lab Invest 1977;37:397-401.

${ }^{2}$ Gerson B, Cohen SR, Gerson IM, Guest GH. Myelin basic protein, oligoclonal bands, and IgG in cerebrospinal fluid as indicators of multiple sclerosis. Clin Chem 1981;27:1974-7.

${ }^{3}$ Thompson EJ, Kaufmann P, Shortman RC, Rudge P, McDonald WI. Oligoclonal immunoglobulins and plasma cells in spinal fluid of patients with multiple sclerosis. Br Med J 1979;1:16-7.

${ }^{4}$ Sidén $\AA$, Kjellin KG. CSF protein examinations with thin-layer isoelectric focussing in multiple sclerosis. $J$ Neurol Sci 1978;39:131-46.

${ }^{5}$ Laurenzi MA, Link H. Comparison between agarose gel electrophoresis and isoelectric focussing of CSF for demonstration of oligoclonal immunoglobulin bands in neurological disorders. Acta Neurol Scand 1978;58:148-56.

- Johnson KP. Cerebrospinal fluid and blood assays of diagnostic usefulness in multiple sclerosis. Neurology (Minneap) 1980;30:106-9.
${ }^{7}$ Link H, Laurenzi MA. Immunoglobulin class and light chain type of oligoclonal bands in CSF in multiple sclerosis determined by agarose gel electrophoresis and immunofixation. Ann Neurol 1979;6:107-10.

${ }^{8}$ Keshgegian AA, Coblentz J, Lisak RP. Oligoclonal immunoglobulins in cerebrospinal fluid in MS. Clin Chem 1980;26:1340-5.

9 Tibbling G, Link H, Öhman S. Principles of albumin and IgG analyses in Neurological Disorders I. Establishment of Reference Values. Scand J Clin Lab Invest 1977;37:385-90.

${ }^{10}$ Link H, Tibbling G. Principles of albumin and IgG analyses in Neurological Disorders III. Relation of the concentration of proteins in serum and cerebrospinal fluid. Scand J Clin Lab Invest 1977;37:391-6.

1 Tourtellotte WW. On cerebrospinal fluid immunoglobulin $\mathrm{G}$ (IgG) quotients in multiple sclerosis and other diseases. A review and a new formulae to estimate the amount of IgG synthesised per day by the central nervous sytem. J Neurol Sci 1970;10:279-304.

12 Bloomer LC, Bray PF. Relative value of three laboratory methods in the diagnosis of multiple sclerosis. Clin Chem 1981;27:2011-3.

${ }^{13}$ McAlpine D. The benign form of multiple sclerosis. A study based on 241 cases seen within three years of onset and followed up until the tenth year or more of the disease. Brain 1961;84:186-203.

${ }^{14}$ McDonald WI, Halliday AM. Diagnosis and classification of multiple sclerosis. $\mathrm{Br}$ Med Bull 1977;33:4-9.

15 Laurell C-B. Electroimmunoassay. Scand J Clin Lab Invest 1972;29:suppl. 124, 21-37.

16 Jeppson J-O, Laurell C-B, Franzén B. Agarose gel electrophoresis. Clin Chem 1979;25:629-38.

${ }^{17}$ Ritchie RF, Smith R, Immunofixation. 1. General principles and application to agarose gel electrophoresis Clin Chem 1976;22:497-9.

${ }^{18}$ Sidén $\AA$, Kjellin KG. Isoelectric focusing of CSF proteins in known or probable infectious neurological diseases and the Guillain-Barré Syndrome. $J$ Neurol Sci 1979;42:139-53.

${ }^{19}$ Link H. Comparison of electrophoresis on agar gel and agarose gel in the evaluation of gamma-globulin abnormalities in cerebrospinal fluid and serum in multiple sclerosis. Clin Chim Acta 1973;46:383-9.

${ }^{20}$ Strony LP, Wagner K, Keshgegian AA. Demonstration of cerebrospinal fluid oligoclonal banding in neurologic diseases by agarose gel electrophoresis and immunofixation. Clin Chim Acta 1982;122:203-12. 
${ }^{21}$ Gerson B, Krolikowski FJ, Gerson IM. Two agarose electrophoretic systems for demonstration of oligoclonal banding in cerebrospinal fluid compared. Clin Chem 1980;26:343-5.

${ }^{22}$ Gerson B, Orr JM. Oligoclonal bands and quantitation of IgG in cerebrospinal fluid as indicators of multiple sclerosis. Am J Clin Path 1980;73:87-91.

${ }^{23}$ Galen RS, Gambino SR. Beyond Normality: the Predictive Value and Efficiency of Medical Diagnosis. New York: John Wiley \& Sons 1975:9-14. 